\title{
PERENCANAAN STRATEGIS SISTEM INFORMASI MENGGUNAKAN ENTERPRISE ARCHITECTURE PLANNING (EAP) FRAMEWORK
}

\author{
Novita Sari Sasue ${ }^{1}$, Agustinus Fritz Wijaya ${ }^{2}$ \\ Program Studi Sistem Informasi \\ Fakultas Teknologi Informasi \\ Universitas Kristen Satya Wacana \\ email : : 682013038@student.uksw.edu ${ }^{1)}$,agustinus.wijaya@uksw.edu ${ }^{2}$ \\ Jalan Dr. O. Notohamijojo No. 1-10, Blotongan, Salatiga - 50715
}

\begin{abstract}
Information Systems strategic planning (SI) is carried out to obtain solutions to the application of SI in organizations. The IS strategic planning process must be managed based on clear guidelines with the aim of aligning strategy and business objectives in the organization. At present, the application of SI in the Semarang City Public Works Department is still not optimal because most of the management of the data is still manual, therefore we need a strategic planning SI whose purpose is that business processes in the organization run effectively and efficiently in supporting the organization's business processes. Enterprise Architecture Planning (EAP) is the process of defining architecture in the use of information to support business and plans to implement the architecture. By using Enterprise Architecture Planning (EAP) can be used as a method to achieve business goals for the City of Semarang Public Works Department, besides it also benefits The application of EAP is to support good decision making and planning in the organization.

Keywords: Strategic Planning, Information Systems, Enterprise Architecture Planning (EAP) Framework
\end{abstract}

\begin{abstract}
Abstrak
Perencanaan strategis Sistem Informasi (SI) dilakukan untuk mendapatkan solusi terhadap penerapan SI di organisasi. Proses perencanaan strategis SI harus dikelola berdasarkan suatu petunjuk yang jelas dengan tujuan untuk menyelaraskan antara strategi dan tujuan bisnis di organisasi. Saat ini, penerapan SI di Dinas Perkerjaan Umum Kota Semarang masih belum optimal dikarenakan sebagian besar pengelolaan datanya masih bersifat manual, maka dari itu dibutuhkan suatu perencanaan strategis SI yang tujuannya adalah proses bisnis dalam organisasi berjalan efektif dan efisien dalam mendukung proses bisnis organisasi. Enterprise Architecture Planning (EAP) merupakan proses pendefinisian arsitektur dalam penggunaan informasi untuk mendukung bisnis dan rencana untuk mengimplementasikan arsitektur tersebut.. Dengan menggunakan Enterprise Architecture Planning (EAP) dapat dijadikan metode untuk mencapai sasaran bisnis bagi Dinas Pekerjaan Umum Kota Semarang, selain itu juga keuntungan dari penerapan EAP adalah untuk mendukung pengambilan keputusan dan perencanaan yang baik di organisasi.
\end{abstract}


Kata kunci: Perencanaan Strategis, Sistem Informasi, Enterprise Architecture Planning (EAP) Framework.

\section{PENDAHULUAN}

Teknologi Informasi (TI) semakin lama semakin maju, setiap saat selalu ada perkembangan yang berpengaruh terhadap berbagai aspek kehidupan. Salah satu diantaranya adalah aspek perekonomian yang berdampak positif bagi perusahaan. Oleh karena itu, setiap perusahaan berusaha untuk menerapkan TI dengan tujuan meningkatkan efektifitas dalam proses bisnis, agar perusahan mampu memberikan nilai tambah berupa keunggulan dalam persaingan bisnis (Kristanto, 2016). Dengan berkembangnya TI saat ini, menuntut perusahaan untuk menjadikan TI sebagai salah satu strategis perusahaan (Mualo \& Budiyanto, 2016). Perusahaan-perusahaan sekarang banyak yang mengandalkan TI untuk mendukung strategi bisnisnya (Riku \& Setyohadi, 2017). Bahkan ada juga perusahaan yang telah menjadikan TI sebagai strategi utama untuk mencapai tujuan perusahaan, baik keuntungan ataupun kelangsungan usaha perusahaan, serta dalam rangka membangun citra perusahaan yang baik, maka perusahaan tersebut perlu menerapkan beberapa strategi dalam berbisnis (Budiyanto \& Setyohadi, 2017). Strategi tersebut dapat melibatkan seluruh komponen, pelaku bisnis sumber daya internal perusahaan secara berkesinambungan dengan memanfaatkan perkembangan TI dalam bidang usaha untuk memperoleh sistem yang efektif dan efisiensi.

Dinas Pekerjaan Umum Kota Semarang adalah Badan usaha milik negara yang bekerja dibidang pelayanan publik daerah Kota Semarang adapun tugasnya adalah melaksanakan urusan pemerintahan daerah di bidang pekerjaan umum, bidang penataan ruang dan bidang lingkungan hidup melalui perumusan kebijakan teknis, pembinaan, fasilitasi dan pelaksanaan kegiatan bina marga, sumber daya air, cipta karya, tata ruang dan tata perkotaan, air bersih, sanitasi dan drainase, pertamanan, persampahan serta pembinaan jasa konstruksi serta tugas lain yang diberikan oleh Walikota sesuai dengan perundang-undangan yang berlaku. Kondisi teknologi yang ada di dalam Dinas Pekerjaan Umum tersebut sebagian besar pengelolaan datanya masih bersifat manual, maka dari itu dibutuhkan suatu perencanaan strategis sistem informasi, yang tujuannya adalah proses bisnis di dalam perusahaan berjalan efektif.

Dalam proses perencanaan strategis terdapat beberapa metode yang sering digunakan, seperti Enterprise Architecture Planning (EAP), TOGAF, DODAF dan Federal enterprise Architecture (FEA). Pada peniltian ini, metode yang digunakan adalah EAP, hal ini dikarenakan metode tersebut memiliki keunggulan lebih, dalam hal adaptasi dan alat-alat pendukung (Nikpay, Ahmad, Rouhani, Mahrin, \& Shamshirband, 2017).

Metode Enterprise Architecture Planning (EAP) merupakan suatu pendekatan yang dibuat oleh Steven H. Spewak untuk membangun arsitektur enterprise dengan berdasarkan dorongan data dan dorongan bisnis. Enterprise Architecture Planning adalah proses pendefinisian arsitektur dalam penggunaan informasi untuk mendukung bisnis dan rencana untuk mengimplementasikan arsitektur tersebut (Spewak, 1992). EAP merupakan proses untuk mendefinisikan kedua top layer dari framework arsitektur sistem informasi Zachman EAP menghasilkan blueprint mengenai data, aplikasi dan teknologi yang menghasilkan solusi jangka panjang. Keuntungan menggunakan EAP adalah penggunaan teknologi yang bersifat strategis untuk mengelola data sebagai sebuah aset dari organisasi dan dapat dijalankan untuk penilaian terhadap dampak perubahan bisnis. 


\section{TINJAUAN PUSTAKA}

\subsection{Enterprise Architecture Planning (EAP)}

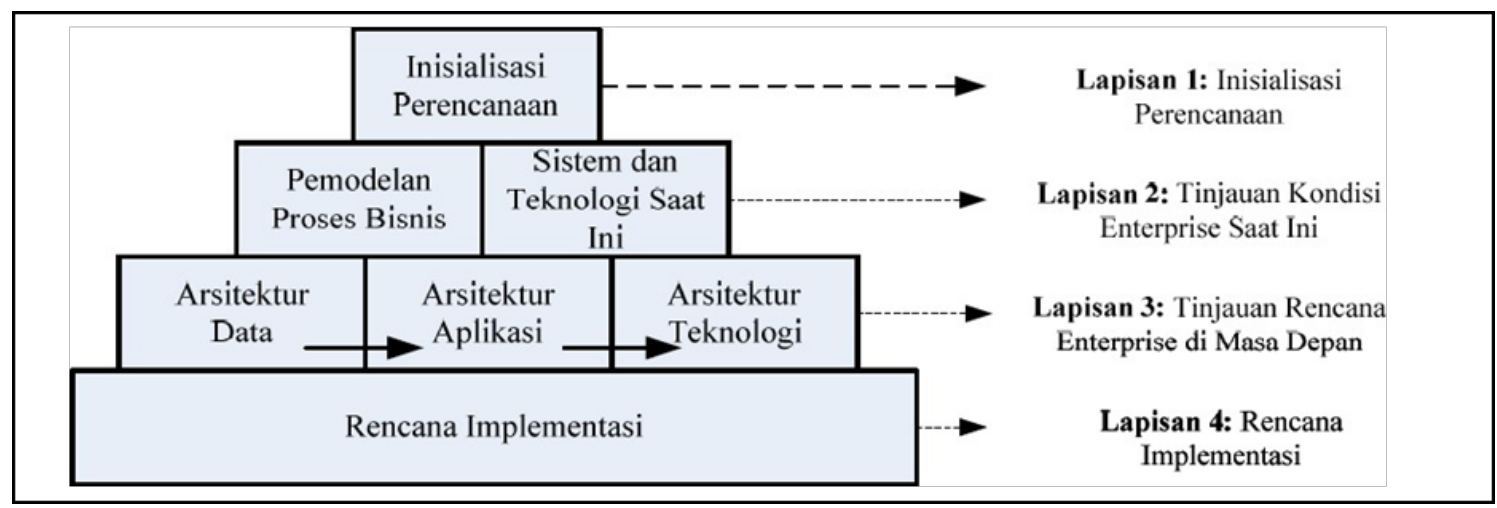

Gambar 1. Lapisan EAP (Spewak \& Hill, 1993)

Enterprise Architecture Planning (EAP) merupakan suatu pendekatan yang dibuat oleh Steven H. Spewak untuk membangun arsitektur enterprise dengan berdasarkan dorongan data dan dorongan bisnis. Enterprise Architecture Planning adalah proses pendefinisian arsitektur dalam penggunaan informasi untuk mendukung bisnis dan rencana untuk mengimplementasikan arsitektur tersebut (Spewak, 1992).

EAP terdiri dari 4 lapisan sebagai berikut:

\section{Inisiasi perencanaan}

Penentuan ruang lingkup enterprise, visi, misi, pengadopsian metodologi perencanaan serta membentuk tim perencanaan agar proyek EAP terarah, selesai tepat waktu dan memiliki anggota tim yang berkualifikasi.

\section{Pemodelan bisnis dan teknologi saat ini}

Dilakukan dengan mengidentifikasi dan mendokumentasikan struktur organisasi, mengidentifikasi dan mendefinisikan area bisnis utama, katalog sumber daya informasi (informatin Resource Catalog, IRC).

\section{Arsitektur data, arsitektur aplikasi dan arsitektur teknologi}

Pendefinisian entitas, Entity Relationship Diagram (ERD), matrik entitas terhadap fungsi, dokumen arsitektur data, pendefinisan aplikasi, materi aplikasi, dokumen arsitektur aplikasi, distribusi data/aplikasi. 


\section{Rencana Implementasi}

Menentukan Kebijakan, standar, prosedur-prosedur, rencana terperinci.

\subsection{Analisis SWOT}

SWOT (strength, weakness, opportunities, threats) merupakan teknik perencanaan strategi untuk mengevaluasi suatu proyek yang sedang berjaan maupun yang sedang dalam perencanaan. Analisis SWOT dibuat untuk mempermudah pengembang agar proyek menjadi lebih terarah.

\begin{tabular}{|c|c|}
\hline SWOT & Analisis \\
\hline Strength & $\begin{array}{ll}\text { - } & \text { Tersediana sumber daya personil } \\
\text { - } & \text { Ketersediaan peralatan penunjang kerja }\end{array}$ \\
\hline Weakness & $\begin{array}{l}\text { - } \text { Belum optimalnya implementasi } \\
\text { - Ketersediaan prasarana belum memadai } \\
\text { - } \quad \text { Pendataan masih secara manual }\end{array}$ \\
\hline Opportunity & $\begin{array}{l}\text { - Adanya tugas pembantuan bidang Pekerjaan Umum dan } \\
\text { Penataan Ruang } \\
\text { - Komitmen pemerintah daerah dalam percepatan pembangunan } \\
\text { infrastruktur ke PU-an dan Penataan Ruang }\end{array}$ \\
\hline Thread & $\begin{array}{l}\text { - Semakin berkurangnya sumber pembiayaan pembangunan } \\
\text { Infrastruktur } \\
\text { - Meningkatnya kebutuhan infrastruktur sejalan dengan } \\
\text { pertumbuhan penduduk }\end{array}$ \\
\hline
\end{tabular}

Tabel 1. Analisi SWOT Dinas Pekerjaan Umum 


\section{METODOLOGI PENELITAN}

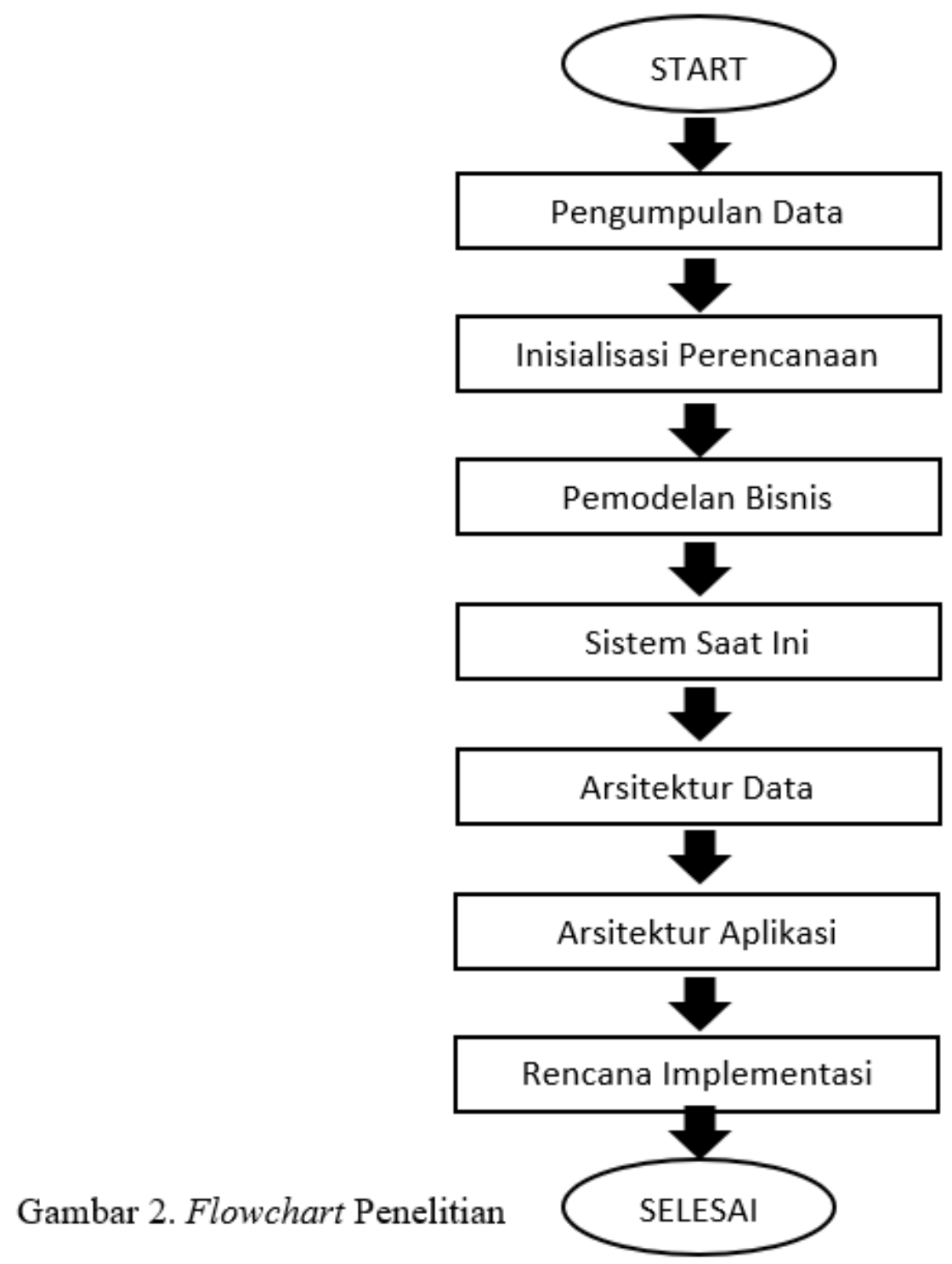

Pada penelitian ini memiliki tahapan seperti pada Gambar 2. Pada proses Pengumpulan Data dilakukan dengan berbagai cara, yaitu Study Literature, Wawancara, dan Observasi. Stud Literature dilakukan pada beberapa jurnal reverensi karena berkaitan dengan topik yang dibahas. Wawancara dilakukan dengan pimpinan dan karyawan karena dianggap terlibat dalam proses bisnis tersebut. Observasi dilakukan dengan cara mengamati langsung di perusahaan tersebut. Inisialisasi perencanaan dilakukan dengan menganalisa model bisnis dan sistem yang sedang berjalan dengan sistem manual. Penerapan arsitektur terdiri dari arsitektur data dan arsitektur aplikasi. Dan langkah terakhir adalah rencana implementasi. 


\section{HASIL DAN PEMBAHASAN}

\section{1 Pemodelan Bisnis}

Pada penelitian ini, pemodelan bisnis yang digunakan Dinas Pekerjaan Umum Kota Semarang yaitu menggunakan analisis Value Chain tujuannya yaitu untuk mengetahui kegiatan apa saja serta mengetahui aktifitas sistem yang sedang berjalan pada Dinas Pekerjaan Umum Kota Semarang. Dalam analisis Value Chain terdapat 2 aktifitas, yaitu aktifitas utama (main activities) dan aktifitas pendukung (support activities).

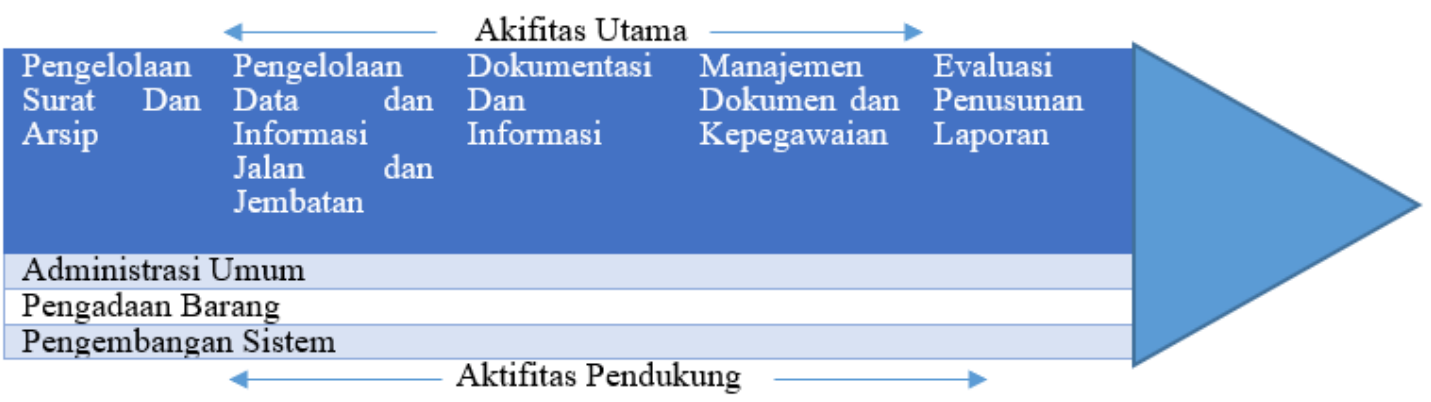

Gambar 3. Value Chain Dinas Pekerjaan Umum Kota Semarang

Aktifitas pendukung, diantaranya adalah: Administrasi Umum, Pengadaan Barang, Pengembangan Sistem. Sedangkan aktifitas utamanya adalah: Pengelolaan Surat dan Arsip, Pengelolaan Data dan Informasi Jalan dan jembatan, Dokumentasi dan Informasi, Manajemen Dokumen dan Kepegawaian, Evaluasi dan Penusunan Laporan.

\section{2 Arsitektur Data}

Arsitektur data dibuat adalah untuk mengelompokkan data berdasarkan entitas data yang telah didefinisikan, entitas yang telah didefinisikan dapat digunakan untuk mendukung fungsi bisnis pada Dinas Pekerjaan Umum Kota Semarang, adapus daftar entitas data Dinas Pekerjaan Umum Kota Semarang sebagai berikut :

Tabel 1: Arsitektur Data

\begin{tabular}{cl}
\hline Entitas Bisnis & \multicolumn{1}{c}{ Entitas Data } \\
\hline Entitas Pelayanan Informasi & 1. Entitas Pendaftaran \\
& 2. Entitas Informasi \\
& 3. Entitas Pengunjung \\
Entitas Gudang & 1. Entitas Barang \\
& 2. Entitas Bon Barang \\
& 3. Entitas Laporan Barang masuk dan Keluar \\
& 4. Entitas Aset
\end{tabular}




\begin{tabular}{cll}
\hline Entitas Bisnis & \multicolumn{1}{c}{ Entitas Data } \\
\hline Entitas Surat dan Arsip & 1. Entitas Surat Masuk \\
& 2. Entitas Surat Keluar \\
& 3. Entitas Laporan Kegiatan \\
& 4. Entitas \\
Entitas Kepegawaian / SDM & 1. Entitas Pegawai \\
& 2. Entitas Gaji Pegawai \\
& 3. Entitas Kinerja Pegawai \\
Entitas Pengelolaan Keuangan & 1. Entitas Anggaran \\
& 2. Entitas Laporan Kegiatan \\
& Entitas Evaluasi Anggaran \\
\hline
\end{tabular}

\section{3 Arsitektur Aplikasi}

Arsitektur Aplikasi dilakukan setelah pendefinisian entitas pada Arsitektur Data, mendefinisikan aplikasi yang dibutuhkan oleh perusahaan untuk mendukung proses bisnis dan pengelolaan database pad perusahaan tersebut. Arsitektur Aplikasi merupakan deskripsi tentang kemampuan dan manfaat dari aplikasi yang digunakan untuk mendukung proses bisnis (Trisminingsih, 2017). Arsitektur Aplikasi diperlihatkan pada Tabel 3.

\begin{tabular}{|c|c|c|c|}
\hline Aktivitas & Kebutuhan & Usulan SI/TI & Keterangan \\
\hline $\begin{array}{l}\text { Pelayanan } \\
\text { Informasi }\end{array}$ & $\begin{array}{c}\text { Membutuhkan web Profil untuk } \\
\text { memberi informasi dan meningkatkan }\end{array}$ & Sistem Informasi & $\begin{array}{l}\text { Mengembangkan } \\
\text { sistem yang }\end{array}$ \\
\hline Pengunjung & pelaanan kepada pengunjung & Pelayanan Publik & sudah ada \\
\hline Gudang & $\begin{array}{l}\text { Memutuhkan Sistem informasi untuk } \\
\text { mengelola Aset dan Barang yang ada } \\
\text { di perusahaan }\end{array}$ & $\begin{array}{l}\text { Sistem Informasi } \\
\text { Gudang }\end{array}$ & $\begin{array}{l}\text { Pembuatan } \\
\text { Sistem baru }\end{array}$ \\
\hline $\begin{array}{l}\text { Penyuratan } \\
\text { dan Arsip }\end{array}$ & $\begin{array}{l}\text { Membutuhkan Sistem untuk mengelola } \\
\text { / menimpan surat dan arsip laporan }\end{array}$ & $\begin{array}{l}\text { Sistem Informasi } \\
\text { E-Document }\end{array}$ & $\begin{array}{l}\text { Pembuatan } \\
\text { Sistem Baru }\end{array}$ \\
\hline $\begin{array}{l}\text { Sumber } \\
\text { Daya } \\
\text { Manusia } \\
\text { (SDM) }\end{array}$ & $\begin{array}{c}\text { Membutuhkan Sistem informasi untuk } \\
\text { mengelola data Karawan }\end{array}$ & $\begin{array}{l}\text { Sistem Informasi } \\
\text { Kepegawaian }\end{array}$ & $\begin{array}{l}\text { Mengembangkan } \\
\text { sistem yang } \\
\text { sudah ada }\end{array}$ \\
\hline $\begin{array}{l}\text { Pengelolaan } \\
\text { Keuangan }\end{array}$ & $\begin{array}{l}\text { Membutuhkan Apliksi untuk } \\
\text { mengelola keuangan, Gaji karawan, } \\
\text { dan pembayaran }\end{array}$ & $\begin{array}{l}\text { Sistem Informasi } \\
\text { Keuangan }\end{array}$ & $\begin{array}{l}\text { Pembuatan } \\
\text { Sistem Baru }\end{array}$ \\
\hline
\end{tabular}


Tujuan dari Arsiektur aplikasi adalah untuk mendefinisikan aplikasi yang dapat digunakan untuk mendukung proses bisnis di Dinas Pekerjaan Umum Kota Semarang. Berdasarkan Tabel 3 usulan sistem informasi yang akan dibuat maupun dikembangkan antara lain: Sistem Informasi Pelayanan Publik, Sistem Informasi Gudang, Sistem Informasi E-Document, Sistem Informasi Kepegawaian, dan Sistem Informasi Keuangan.

\section{4 Rencana Implementasi}

Implementasi Arsitektur Enterprise dibuat untuk perencanaan sistem informasi dan mengembangkan sistem informasi yang sudah ada atau sudah berjalan saat ini. Pengembangan aplikasi dilakukan karena sangat dibutuhkan untuk bebrapa tahun kedepan. Pengembangan aplikasi juga disesuaikan oleh kebutuhan dari organisasi. Betikut ini merupakan gambaran aplikasi strategis yang dibutuhkan.

Tabel 4. Rencana Implementasi

\begin{tabular}{ll}
\hline \multicolumn{1}{c}{ Strategi } & Aplikasi Berpotensi Tinggi \\
\hline Sistem Informasi Gudang & Sistem Informasi Gudang \\
\hline Penyuratan Dan Arsip & Sistem Informasi E- Document \\
\hline Sistem Informasi Sumber Daya Manusia & Sistem informasi Kepegawaian \\
\hline Sistem Informasi Pengelolaan Keuangan & Sistem Informasi Keuangan \\
\hline
\end{tabular}

Tabel 5. Urutan Implementasi Aplikasi

\begin{tabular}{|l|l|l|l|l|l|}
\hline \multicolumn{1}{|c|}{ Nama Aplikasi } & 2020 & 2021 & 2022 & 2023 & 2024 \\
\hline $\begin{array}{l}\text { Sistem Informasi } \\
\text { Kepegawaian }\end{array}$ & & & & & \\
\hline $\begin{array}{l}\text { Sistem Informasi } \\
\text { Keuangan }\end{array}$ & & & & & \\
\hline $\begin{array}{l}\text { Sistem Informasi } \\
\text { Gudang Informasi }\end{array}$ & & & & & \\
\hline $\begin{array}{l}\text { Sistem Informasi E- } \\
\text { Document }\end{array}$ & & & & & \\
\hline $\begin{array}{l}\text { Sistem Pelayanan Publik } \\
\text { Pum }\end{array}$ & & & & & \\
\hline
\end{tabular}


Berdasarkan Tabel 5 diatas, aplikasi yang sedang direncanakan dan aplikasi yang akan dikembangkan membutuhkan waktu 5 tahun. Urutan perencanaan implemetasi aplikasi ini diurutkan berdasar fungsi dari aplikasi yang mendukung kegiatan bisnis Dinas Pekerjaan Umum Kota Semarang.

\section{KESIMPULAN}

Berdasarkan Studi kasus yang telah dilakukan di Dinas Pekerjaan Umum Kota Semarang bahwa penerapan metode EAP merupakan strategi yang dapat digunakan untuk membantu menyelaraskan bisnis yang ada dan Teknologi yang sudah berjalan. Metode ini dapat mengidentifikasi mulai dari proses bisnis sampai ke perencanaan implementasi sistem informasi yang akan dibuat.

Berdasarkan analisa mulai dari aktifitas utama sampai aktifitas pendukung maka diperoleh portofolio aplikasi sistem informasi pada Dinas Pekerjaan Umum Kota Semarang yang diantaranya adalah Sistem Informasi Pelayanan Publik, Sistem Informasi E- Document, Sistem Informasi Gudang, Sistem Informasi Keuangan, dan Sistem Informasi Kepegawaian, dimana dalam perencanaan aplikasi tersebut hasil proses bisnis Dinas Pekerjaan Umum Kota Semarang dapat berjalan lebih efektif. Dengan Enterprise Architecture Planning (EAP) dapat dijadikan metode untuk mencapai sasaran bisnis Dinas Pekerjaan Umum Kota Semarang, selain itu keuntungan EAP adalah untuk mendukung pengambilan keputusan dan perencanaan yang baik.

\section{Referensi}

Budiyanto, D., \& Setyohadi, D. B. (2017). Strategic information system plan for the implementation of information technology at Polytechnic "API" Yogyakarta. 2017 5th International Conference on Cyber and IT Service Management (CITSM). Denpasar: IEEE.

Mualo, A., \& Budiyanto, A. D. (2016). Perencanaan strategis sistem informasi menggunakan TOGAF (Studi kasus: Universitas Satria Makassar). Seminar Riset Teknologi Informasi (SRITI) (pp. 294-304). Yogyakarta: STMIK AKAKOM.

Kristanto, T. (2016). Enterprise Architecture Planning Untuk Proses Pengelolaan Manajemen Aset Dengan Zachman Framework. Register: Jurnal Ilmiah Teknologi Sistem Informasi, 2(2), 98-104.

Riku, M. O., \& Setyohadi, D. B. (2017). Strategic plan with enterprise architecture planning for applying information system at PT. Bestonindo Central Lestari. 2017 5th International Conference on Cyber and IT Service Management (CITSM). Denpasar: IEEE.

Nikpay, F., Ahmad, R. B., Rouhani, B. D., Mahrin, M. N., \& Shamshirband, S. (2017). An effective Enterprise Architecture Implementation Methodology. Information Systems and e-Business Management, 15(4), 927-962.

Spewak, S. H., \& Hill, S. C. (1993). Enterprise architecture planning: developing a blueprint for data, applications and technology. Enterprise architecture planning: developing a blueprint for data, applications and technology. Boston: QED Information Sciences.

Trisminingsih, R. (2017). Perancangan Arsitektur Enterprise untuk Koperasi pertanian menggunakan Enterprise Architecture Planning (Eap). Media Jurnal Informatika Vol. 7 Periode Juli 2015, 7(01), 1829. 